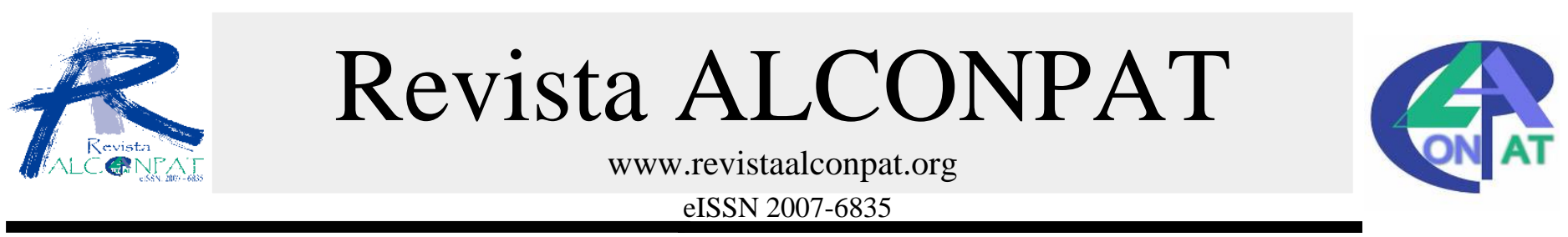

Revista de la Asociación Latinoamericana de Control de Calidad, Patología y Recuperación de la Construcción

\title{
Projeto de estabilização estrutural das paredes de apoio da abóbada central da Igreja de Santa Teresa
}

\author{
R. Muñoz ${ }^{1}$
}

${ }^{1}$ NTPR - Núcleo de Tecnologia da Preservação e da Restauração, Faculdade de Arquitetura, Universidade Federal da Bahia, Salvador de Bahía, Brasil.

\begin{abstract}
Información del artículo
DOI:

http://dx.doi.org/10.21041/ra.v4

$\underline{i 3.69}$

Artículo recibido el 28 de junio de 2014, revisado bajo las políticas de publicación de la Revista ALCONPAT y aceptado el 15 de agosto de 2014. Cualquier discusión, incluyendo la réplica de los autores, se publicará en el segundo número del año 2015 siempre y cuando la información se reciba antes del cierre del primer número del año 2015.
\end{abstract}

\section{(c) 2014 ALCONPAT Int.}

Información Legal

Revista ALCONPAT, Año 4, No. 3, Septiembre - Diciembre 2014, es una publicación cuatrimestral de la Asociación Latinoamericana de Control de Calidad, Patología y Recuperación de la Construcción, Internacional, A.C., Av. Zamná No. 295 entre 61 y 63 Fraccionamiento Yucalpetén, Mérida, Yucatán, México, C.P. 97248, Tel.5219997385893.

alconpat.int@gmail.com, Página Web: alconpat.int@gmail

Editor responsable: Dr. Pedro Castro Borges Reserva de derechos al uso exclusivo No.04 2013-011717330300-203, eISSN 2007-6835, ambos otorgados por el Instituto Nacional de Derecho de Autor. Responsable de la últim actualización de este número, Unidad de Elizabeth Sabide Maldonado, Av. Zamná No. 295 entre 61 y 63 Fraccionamiento Yucalpetén, Mérida Yucatán, México, C.P. 97248 , fecha de publicación: 30 de septiembre de 2014

Las opiniones expresadas por los autores no necesariamente reflejan la postura del editor. Queda totalmente prohibida la reproducción total o parcial de los contenidos e imágenes de la publicación sin previa autorización de la ALCONPAT Internacional A.C.

\section{RESUMO}

A Igreja e o Convento de Santa Teresa, datados da segunda metade do século XVII e localizados em Salvador, Bahia, Brasil, compõem um importante conjunto arquitetônico tombado pelo Instituto do Patrimônio Histórico e Artístico Nacional. A Igreja apresenta uma arquitetura de transição entre o Renascimento e o Barroco, com interior do século XVIII. O teto de sua nave é constituído por uma abóbada, de alvenaria de tijolos sobre arcos de pedra aparelhada, que se apoia em paredes portantes, construídas em alvenaria de pedra, que se apresentam com fissuras e desaprumadas. Após análise detalhada, concluiu-se que esses danos ocorreram em função do empuxo horizontal exercido pela abóbada. O objetivo deste artigo é apresentar a solução para estabilização das paredes de apoio da abóbada central, com a utilização de tirantes metálicos. Como resultados, serão apresentados os detalhes do projeto de estabilização das paredes e a técnica para conter o desaprumo.

Palavras chave: patrimônio; estabilização; estrutura; tirantes.

\section{ABSTRACT}

The Church and Convent of Santa Teresa, dating from the second half of the seventeenth century and located in Salvador, Bahia, Brazil, comprise an important architectural complex listed by the Instituto do Patrimônio Histórico e Artístico Nacional. The Church presents an architecture style between the Renaissance and Baroque, with interior of the eighteenth century. The roof of its central aisle consists of a dome, brick masonry arches carved stone on which rests on freestanding walls, built in stone masonry, presenting cracks and without plumb. After detailed analysis it was concluded that these damages occur due to the horizontal thrust exerted by the dome. The objective of this paper is to present the solution to stabilize the walls supporting the central dome using metal rods. Results present the design details of stabilizing walls and technique used to contain the lack of plumb.

Keywords: heritage; stability; structure; rods.

Autor de contato: Rosana Muñoz (munoz.rosana@gmail.com) 


\section{INTRODUÇÃO}

O conjunto arquitetônico de Santa Teresa, composto pela Igreja e pelo Convento, que hoje abriga o Museu de Arte Sacra da Bahia, está localizado sobre o mar, na colina da Baía de Todos os Santos, em Salvador, Bahia, Brasil (Figuras 1 e 2). Datados da segunda metade do século XVII, compõem um importante monumento que foi tombado pelo Instituto do Patrimônio Histórico e Artístico Nacional em 1984.

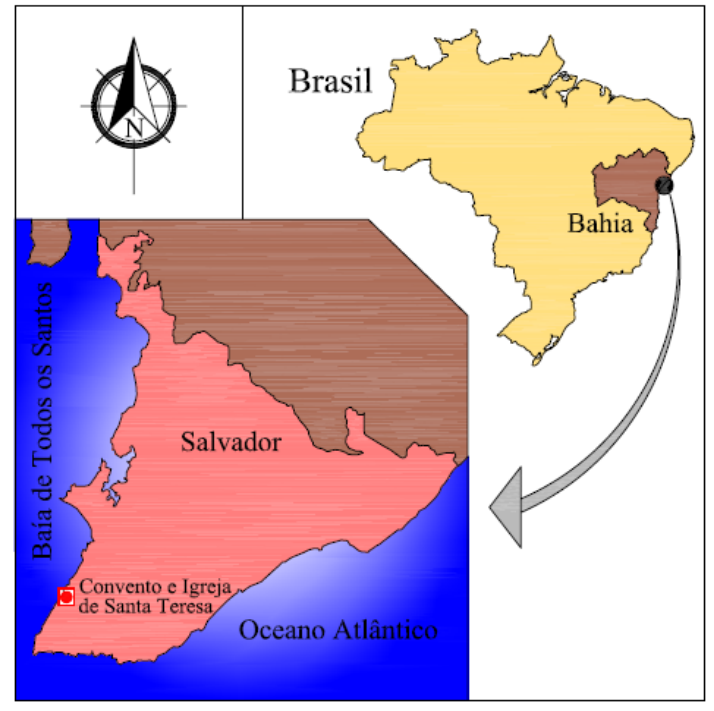

Figura 1. Localização do Convento e Igreja de Santa Teresa.

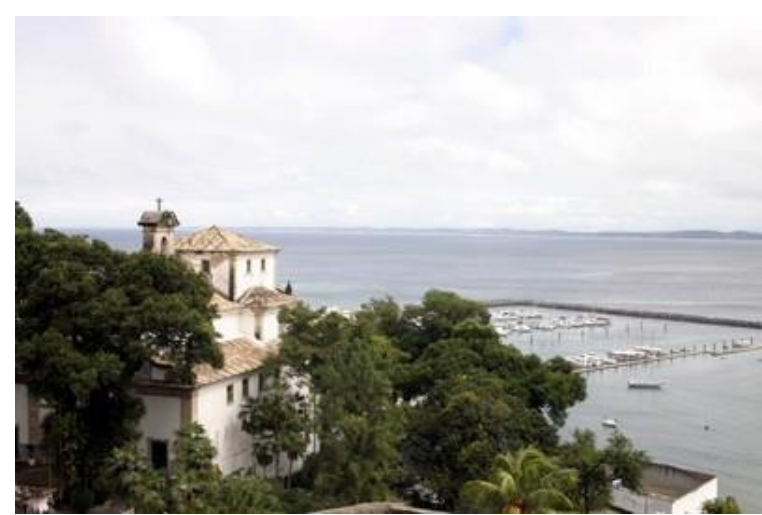

Figura 2. Vista do conjunto arquitetônico de Santa Teresa.

A construção desse notável cenóbio teve sua origem em um acontecimento casual. Provavelmente pelos anos de 1661 ou 1662, chegaram à Bahia seis carmelitas descalços que se dirigiam a Angola com intenção de fundar um convento por ordem do Rei. A falta de embarcações, coisa muito frequente naqueles tempos, obrigou-os a permanecer durante oito meses na Capital, onde sofreram toda sorte de desconfortos e até doenças, que os atribuíram à falta de um hospício onde pudessem se recolher (Calderón, 1981).

$\mathrm{O}$ zelo e a caridade demonstrados durante a permanência na Bahia, atendendo onde eram chamados, assim como a piedade no culto e os sermões proferidos, propiciaram um ambiente acolhedor que eles aproveitaram para lançar a ideia da fundação de um hospício terésio na Cidade do Salvador, promissora capital da colônia portuguesa. Assim, em 25 de junho de 1665, obtiveram uma Carta Régia que os autorizava a fundá-lo.

A Igreja de Santa Teresa (Figura 3), objeto do presente trabalho, apresenta uma arquitetura de transição entre o Renascimento e o Barroco. Tem seu espaço interno definido pelos elementos arquitetônicos de cantaria com partido de planta em cruz latina, de nave única, precedida por um pórtico de três arcos, coberto com abóbadas de arestas, sobre o qual se apoia parte do coro alto, suspenso sobre um grande arco abatido bem rebaixado, apoiado em impostas. O teto da nave é constituído por uma abóbada de penetração (Figura 4), construída em alvenaria de tijolos, com 30 centímetros de espessura e 8,15 metros de vão, sobre arcos de pedra aparelhada. $\mathrm{O}$ edifício possui a maior parte de sua estrutura em paredes construídas em alvenaria de pedra com argamassa à base de cal (IPAC-BA, 1978). 


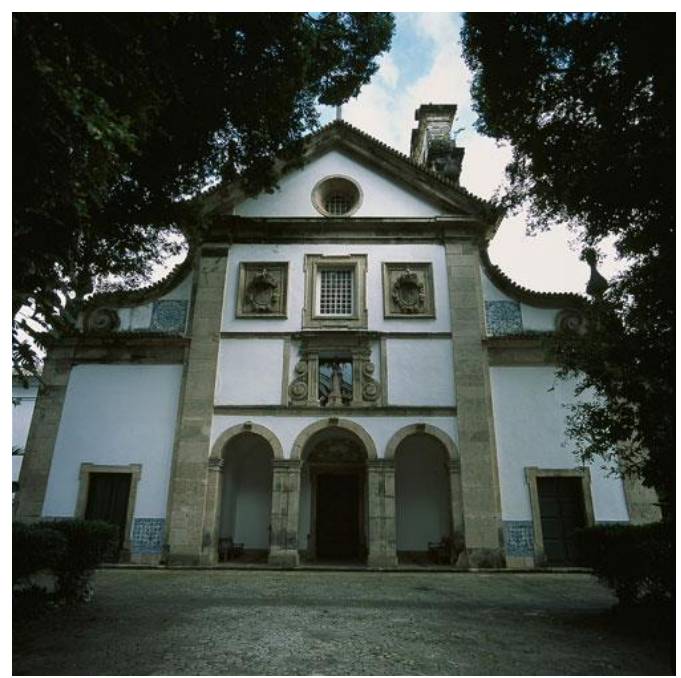

Figura 3. Vista da Igreja de Santa Teresa.

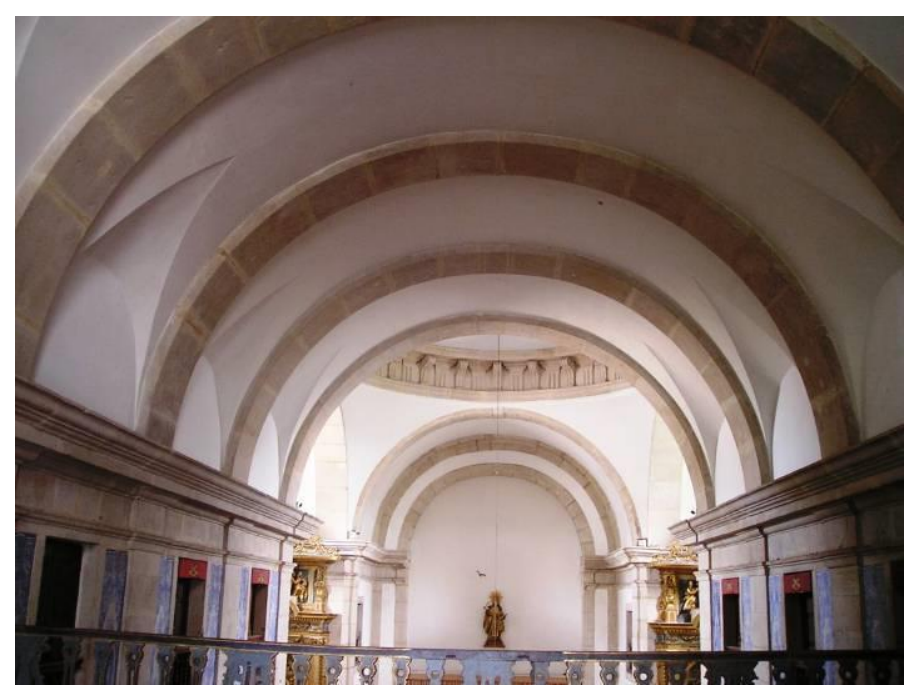

Figura 4. Vista da abóbada da nave.

De acordo com Calderón (1981, p. 36), pouco se sabe a respeito da construção do edifício seiscentista, "feito polo mesmo risco e prospeto dos mais que esta ordem possuía em Portugal" em uma alusão à semelhança com o convento dos Remédios de Évora, em Portugal, também da mesma ordem.

Segundo Smith, citado por Calderón (1970), o partido da fachada de Santa Teresa obedece ao primeiro desenho que Vignola elaborou para a igreja de Gesù de Roma, em 1569, e classifica a Igreja de Santa Teresa como sendo uma interpretação única, no Brasil, de um tipo de fachada de modelo romano usado antes do fim do século XVII, assemelhada à de Santo Inácio de Roma.

Bazin (1956) afirma que seu campanário assemelha-se ao da Igreja de Trindade de Salamanca, construída na mesma época. Outra igreja que apresenta forte analogia com Santa Teresa é a de Aveiros, em Portugal, terminada em 1643, cuja fachada é idêntica àquela e à de Santa Teresa em Ávila, na Espanha (Calderón, 1970).

A Igreja une-se ao Convento através de um claustro, com partido raro de um só piso, assemelhado ao da Igreja de Nossa Senhora dos Remédios, em Évora, Portugal, possuindo corredores laterais cobertos em abóbadas de arestas de alvenaria de tijolos. Possui pilastras sequenciadas e pilares colocados sobre parapeitos de cimo abaulado em suas arcadas, em uma primorosa harmonia do conjunto de acentuada modenatura renascentista (Calderón, 1970).

O monumento passou por uma série de reformas por apresentar diversas patologias. Delas, restalhe, ainda, a presença de fissuras. $\mathrm{O}$ diagnóstico mais detalhado indicou desaprumo das paredes que sustentam a abóbada central, em função do empuxo horizontal exercido pela abóbada. O objetivo deste artigo é apresentar a solução para estabilizar as alvenarias de apoio da abóbada central e conter o desaprumo.

Para o desenvolvimento do presente trabalho, foram realizadas as seguintes etapas: levantamento cadastral; retirada de amostras de materiais para análise laboratorial, com o objetivo de obter parâmetros para avaliação dos esforços e para o restauro; cálculos das solicitações pelo método dos elementos finitos, com a utilização de software estrutural; análise dos resultados; dimensionamento das peças estruturais de estabilização; e execução do projeto. Como resultados, serão apresentados os detalhes do projeto de estabilização das paredes e a técnica para aprumálas. 


\section{VERIFICAÇÃO DA ESTABILIDADE}

Para a verificação da estabilidade e cálculo do empuxo da abóbada central da Igreja de Santa Teresa, inicialmente, foi feito o levantamento cadastral, com identificação do trecho mais solicitado (Figura 5). Posteriormente, foram retiradas amostras de materiais e realizados ensaios no laboratório do NTPR - Núcleo de Tecnologia da Preservação e da Restauração, vinculado à Pós-Graduação de Arquitetura e Urbanismo, da Faculdade de Arquitetura, e ao DCTM Departamento de Ciência e Tecnologia dos Materiais, da Escola Politécnica, ambos da Universidade Federal da Bahia.

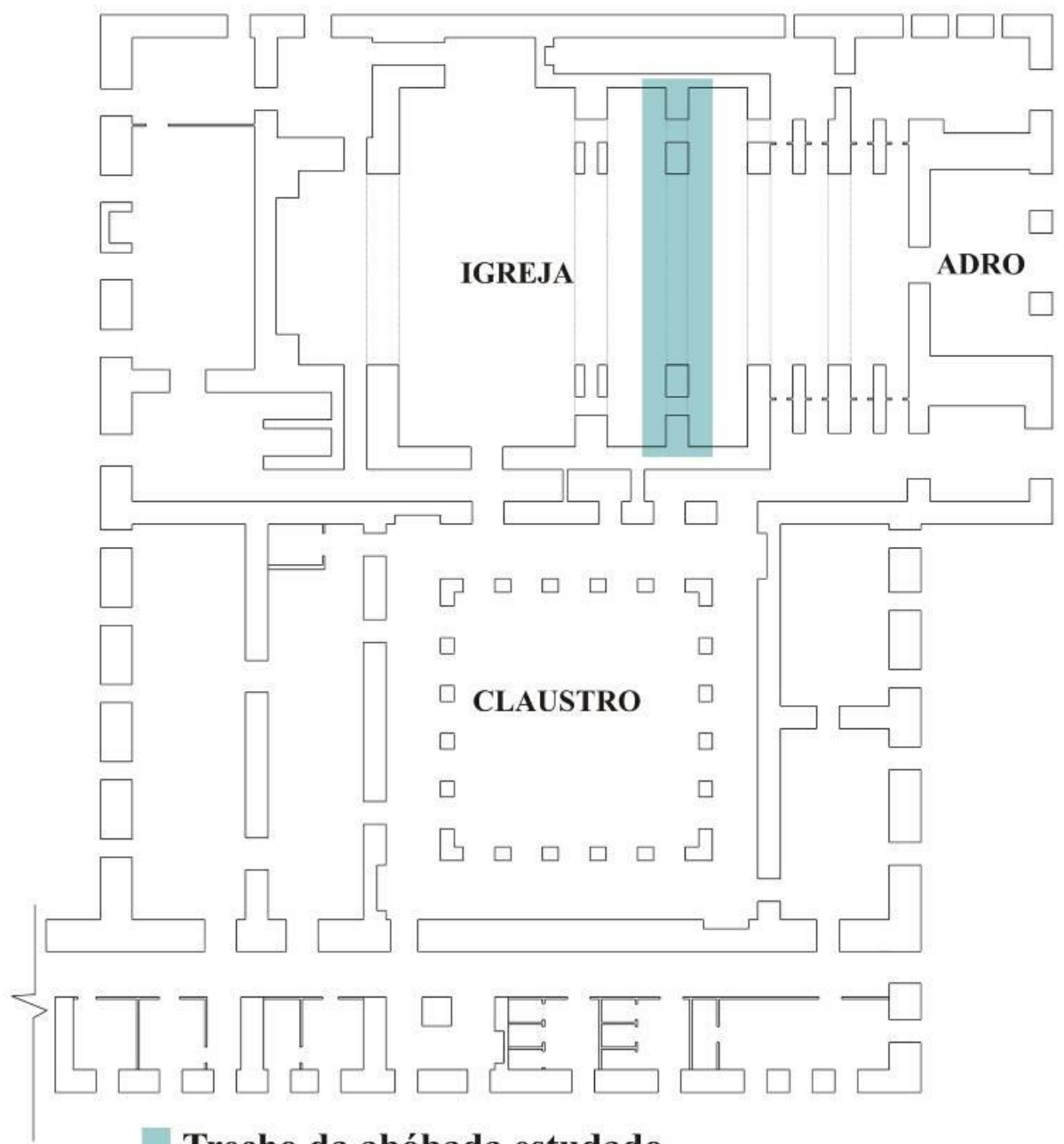

Trecho da abóbada estudado.

Figura 5. Trecho mais solicitado da abóbada em estudo.

Os materiais extraídos da abóbada central para análise foram: tijolo, argamassa da abóbada e argamassa do enchimento lateral (Figura 6). Os ensaios realizados nas amostras estão dispostos na Tabela 1. 


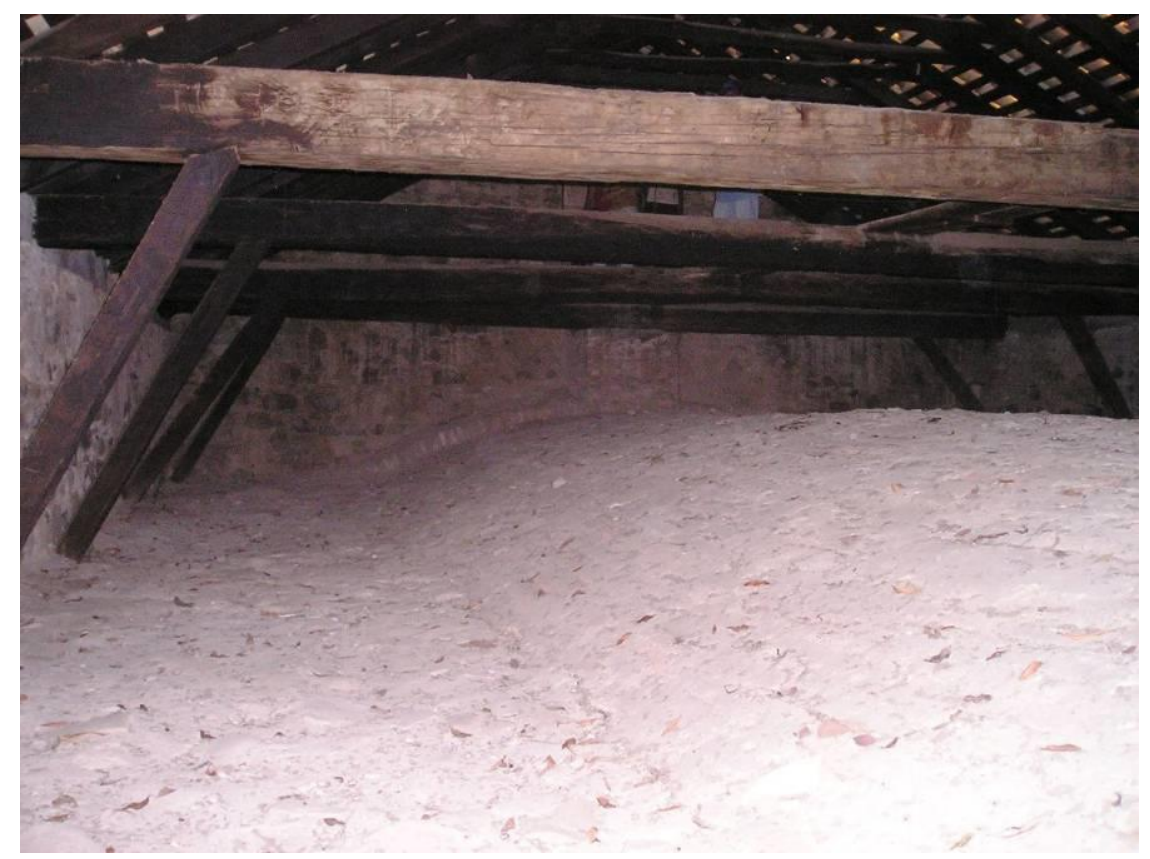

Figura 6. Vista superior da abóbada, do enchimento lateral e das tesouras.

Tabela 1. Ensaios realizados nas amostras de Santa Teresa

\begin{tabular}{|c|c|}
\hline Material & Ensaios \\
\hline \multirow{2}{*}{ Tijolo } & Absorção total em água \\
\hline & Densidade com o Picnômetro de Hubbard \\
\hline \multirow{4}{*}{$\begin{array}{c}\text { Argamassa da } \\
\text { abóbada e do } \\
\text { enchimento lateral }\end{array}$} & Teste qualitativo para identificação de presença de sais solúveis \\
\hline & Identificação do traço em massa \\
\hline & Granulometria do agregado após ataque ácido e remoção dos finos \\
\hline & Densidade com o Picnômetro de Hubbard \\
\hline
\end{tabular}

Da análise dos resultados dos ensaios, ressalta-se a presença de sais na argamassa da abóbada (grande quantidade de cloreto e média de sulfato), provavelmente pela proximidade do aerossol salino ou outro tipo de contaminação, e traço 1:2 (uma medida de cal para duas de areia). A presença de argila é insignificante, podendo ser proveniente da areia. $\mathrm{Na}$ argamassa de enchimento, obteve-se pequena quantidade de cloreto e sulfato; e mesmo traço, 1:2.

O ensaio de densidade com o Picnômetro de Hubbard permitiu identificar o peso específico do tijolo e da argamassa, dados imprescindíveis para o cálculo do empuxo. Os resultados dos pesos específicos, fazendo-se a média ponderada entre os materiais, foram: para alvenaria de tijolo, $19,77 \mathrm{kN} / \mathrm{m}^{3}$; e para o enchimento superior, em pedra argamassada, $23,75 \mathrm{kN} / \mathrm{m}^{3}$. Os outros ensaios realizados e não destacados aqui neste texto foram importantes para a recomposição da argamassa quando da execução de procedimentos de restauro.

A etapa seguinte compreendeu o carregamento da abóbada, cujas considerações de cálculo foram: arco pleno; sobrecarga de $0,50 \mathrm{kN} / \mathrm{m}^{2}$ (Associação Brasileira de Normas Técnicas, 1980, p. 4); espessura do material da arquivolta e dos apoios: $30 \mathrm{~cm}$ de espessura da camada de argamassa e tijolo (Figura 7), com peso específico $19,77 \mathrm{kN} / \mathrm{m}^{3}$, conforme cálculo realizado previamente, e 17 
cm de pedra arenito (Figura 7), com peso específico 26,00 kN/m $\mathrm{m}^{3}$ (Associação Brasileira de Normas Técnicas, 1980, p. 2); enchimento lateral em pedra argamassada (Figura 7) com peso específico $23,75 \mathrm{kN} / \mathrm{m}^{3}$, conforme cálculo realizado anteriormente; vão teórico de $8,5 \mathrm{~m}$ e largura de um metro; e telhado descarregando na alvenaria.

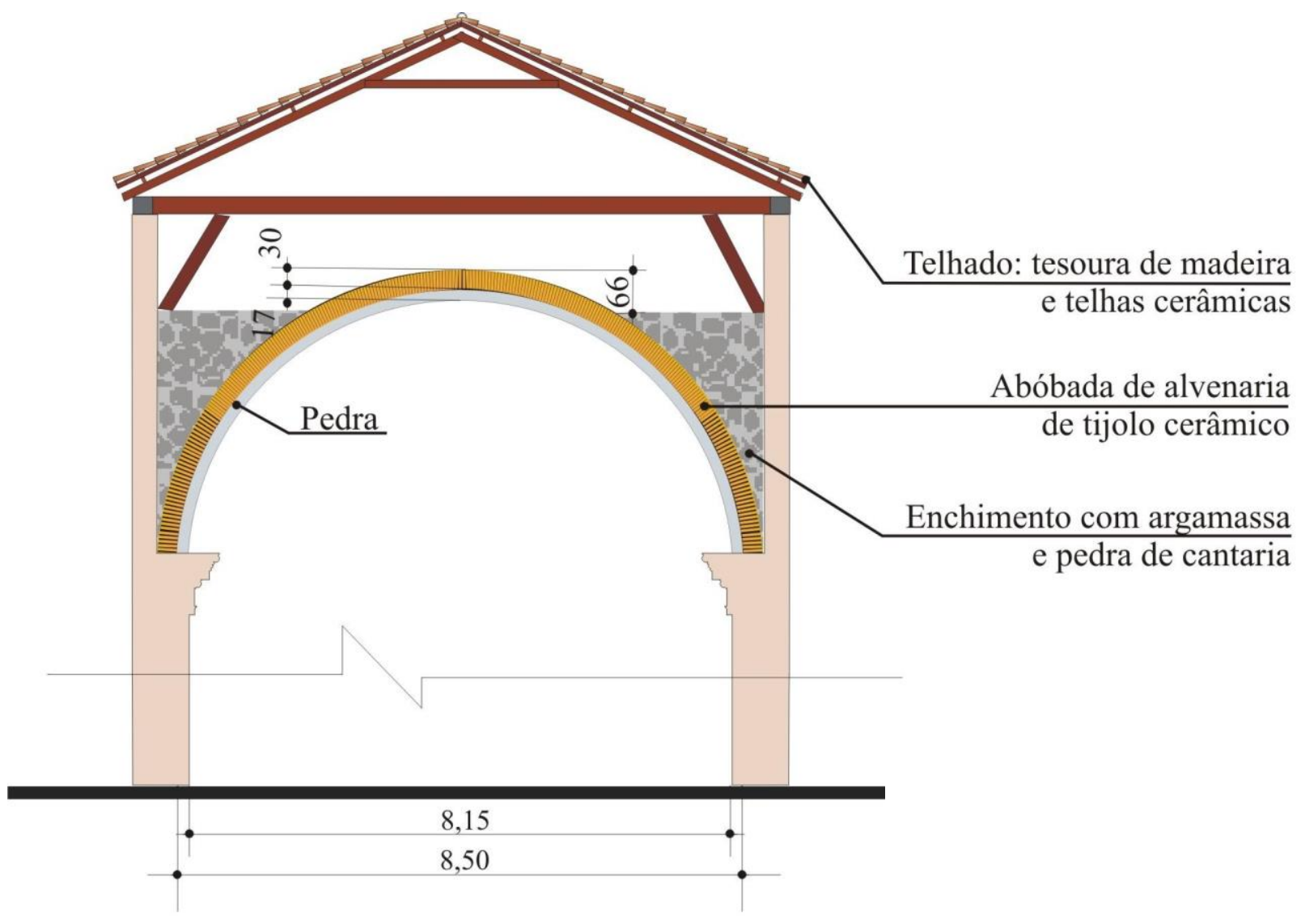

Figura 7. Seção transversal da abóbada central.

O cálculo dos esforços foi realizado com o auxílio do software SAP2000 Plus, que utiliza o método os elementos finitos. Como resultado do esforço horizontal (empuxo), para um metro de abóbada, obteve-se 2843 kgf (somatório dos valores 561,92; 571,93; 575,23; 571,93; 561,92; mostrados na Figura 8), correspondendo a 28,43 kN.

Para o cálculo da resultante dos esforços verticais e horizontais, foram considerados o empuxo e a força vertical obtida pelo maciço de apoio, parede e telhado, que neste caso totalizou 643,16 $\mathrm{kN}$. Uma vez que a resultante das solicitações não está compreendida no terço médio do maciço, o que gera uma estrutura instável, foi proposto um sistema de consolidação com a utilização de tirantes metálicos, abordado na seção seguinte. 


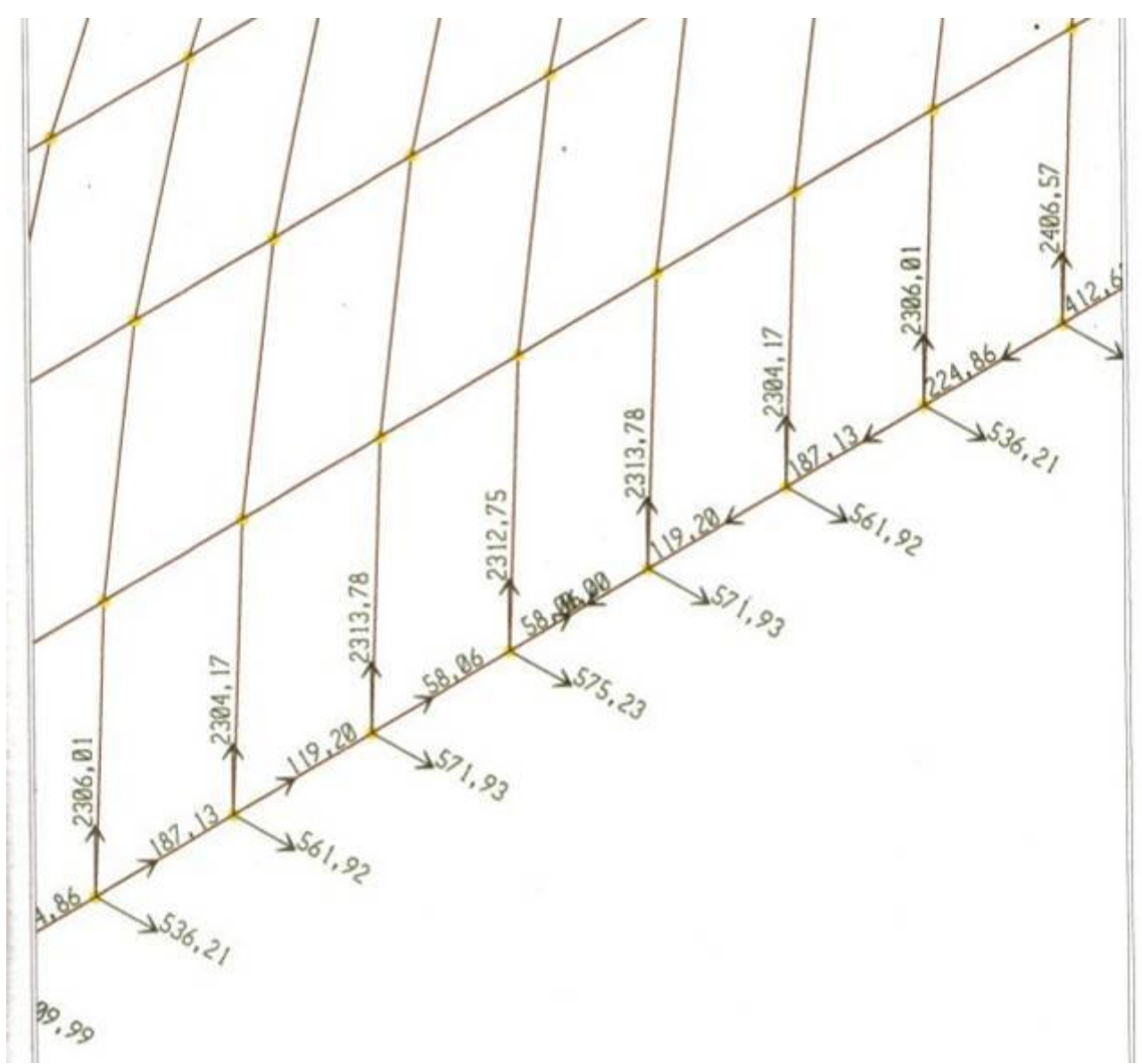

Figura 8. Esforços, considerando uma faixa de um metro de abóbada.

\section{ESTABILIZAÇÃO ESTRUTURAL}

O tirante metálico foi dimensionado pela fórmula da tensão, considerando aço SAE 1020, com tensão admissível de $14,00 \mathrm{kN} / \mathrm{cm}^{2}$, recomendado pela possibilidade de abertura de rosca, e coeficiente de segurança de majoração da carga igual 1,4. Foi obtido o diâmetro de $20 \mathrm{~mm}$.

Os tirantes deverão ser fixados na parede com a utilização de esbarros metálicos quadrados, de 20 cm x $20 \mathrm{~cm}$ (Figura 9). O espaçamento entre eles será de $154 \mathrm{~cm}$ (Figura 10), valor calculado levando-se em consideração a espessura da alvenaria e a distribuição dos esforços a $45^{\circ}$, a partir dos esbarros.

O esbarro foi verificado segundo a metodologia apresentada por Oliveira (2011, p. 202):

$$
F=\sigma_{0} \cdot 2 \cdot E \cdot \sqrt{2}(a+b)
$$

Onde:

$\mathrm{F}=$ Força admissível no tirante

$\sigma_{0}=$ Tensão admissível no muro

$\mathrm{E}=$ espessura da parede

$\mathrm{a}=$ lado da base maior do tronco de pirâmide do esbarro

$\mathrm{b}=$ lado da base menor do tronco de pirâmide do esbarro 


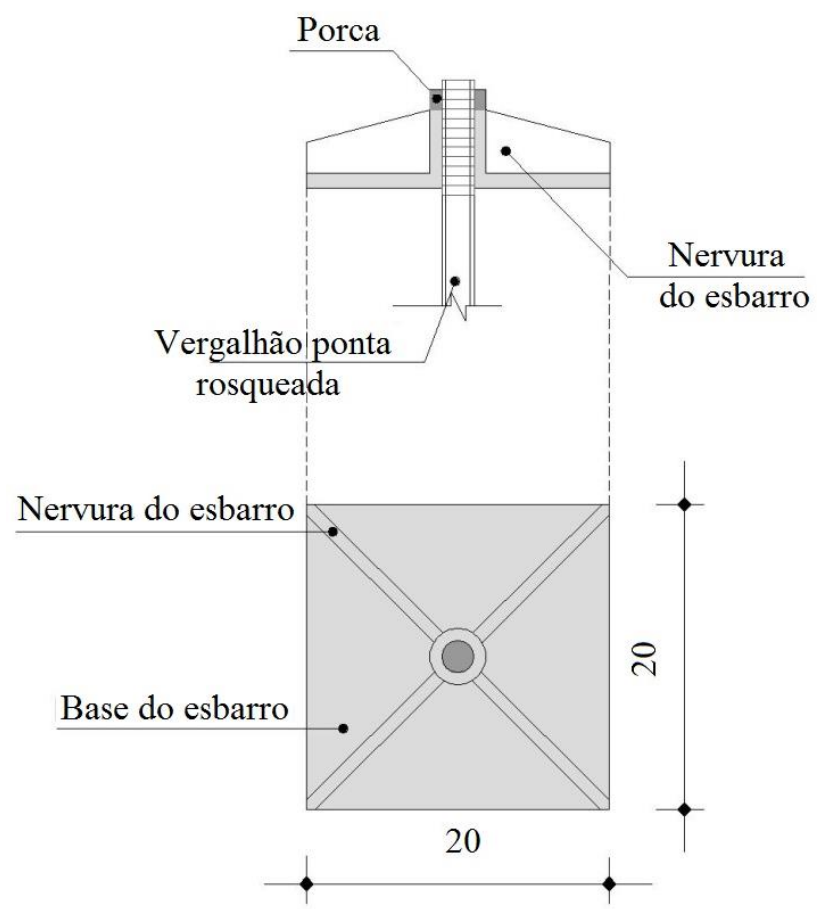

Figura 9. Detalhe do esbarro (medidas em centímetros).

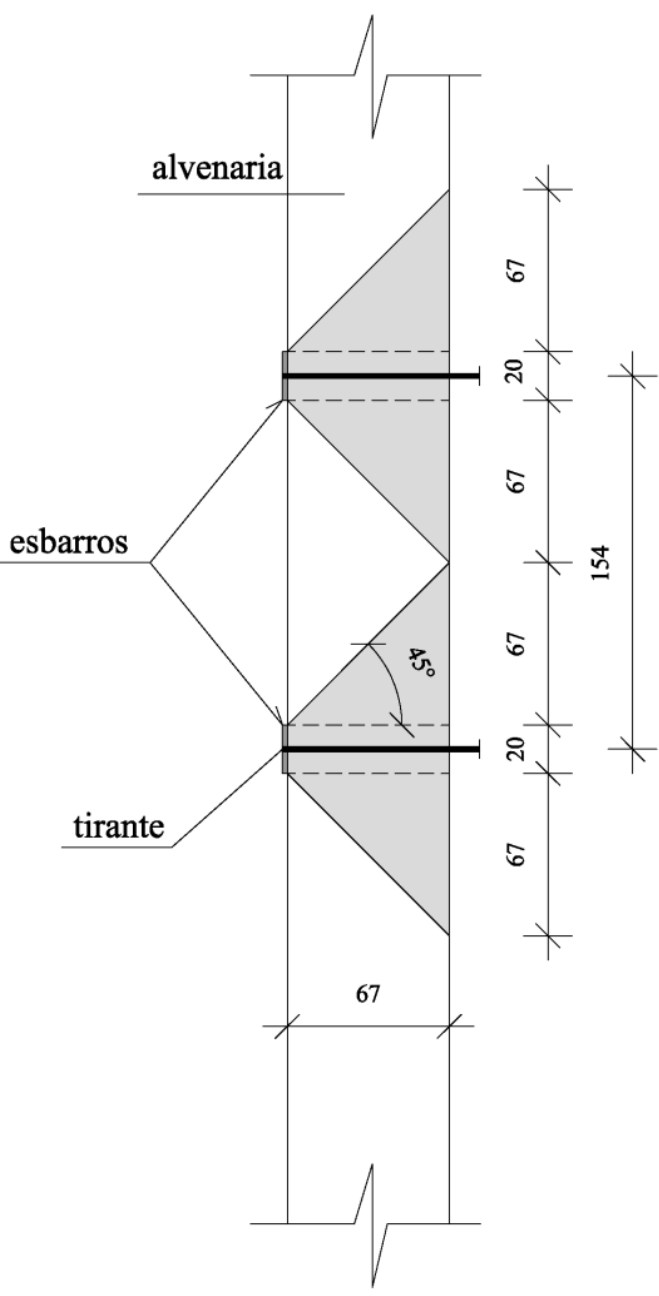

Figura 10. Detalhe do espaçamento dos tirantes, em planta (medidas em centímetros).

No caso em estudo, os parâmetros são: $\sigma_{0}=0,0015$ kN/cm² (Oliveira, 2011, p. 202); E = 67 cm; a $=154 \mathrm{~cm} \mathrm{e} \mathrm{b}=20 \mathrm{~cm}$. Substituindo esses valores em (1), tem-se $\mathrm{F}=49,46 \mathrm{kN}$, que é superior à força de trabalho 1,4 x 28,43 = 39,80 kN. Os esbarros de $20 \mathrm{~cm}$ x $20 \mathrm{~cm}$ serão confeccionados com espessuras de meia polegada e colocados $10 \mathrm{~cm}$ abaixo das impostas. Os tirantes ficarão, assim, a uma altura de 8 metros, a contar do piso. As Figuras 11 e 12 mostram, em detalhe, o sistema de estabilização proposto.

Os tirantes metálicos serão apertados com o auxílio de chave de torque para que todos fiquem submetidos ao mesmo esforço e não acentuem a instabilidade da alvenaria. Por meio deste sistema, será contido o desaprumo das alvenarias. 
Revista ALCONPAT, Volumen 4, Número 3, Septiembre - Diciembre 2014, Páginas 192- 201

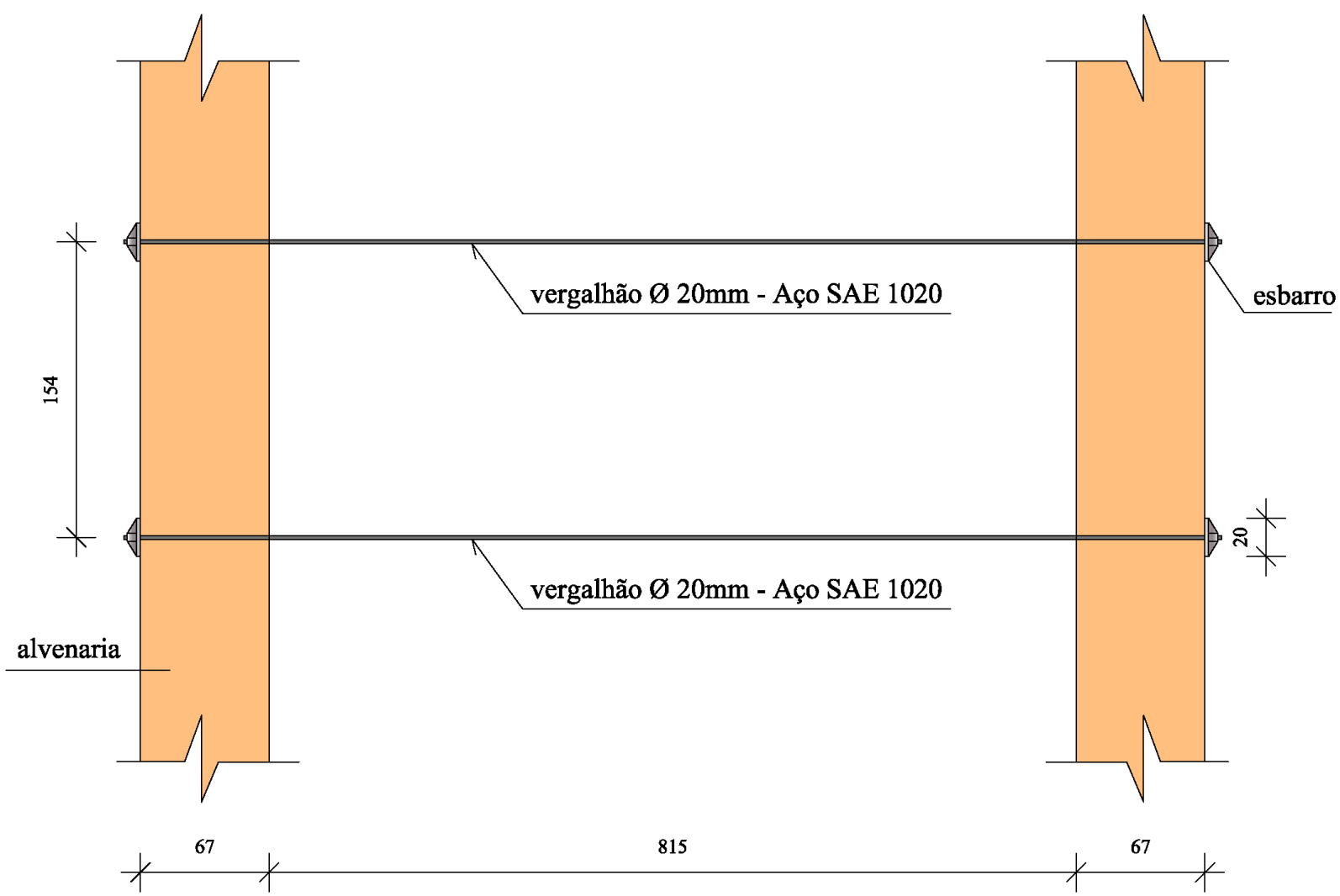

Figura 11. Sistema de estabilização proposto para a alvenaria, em planta (sem escala).

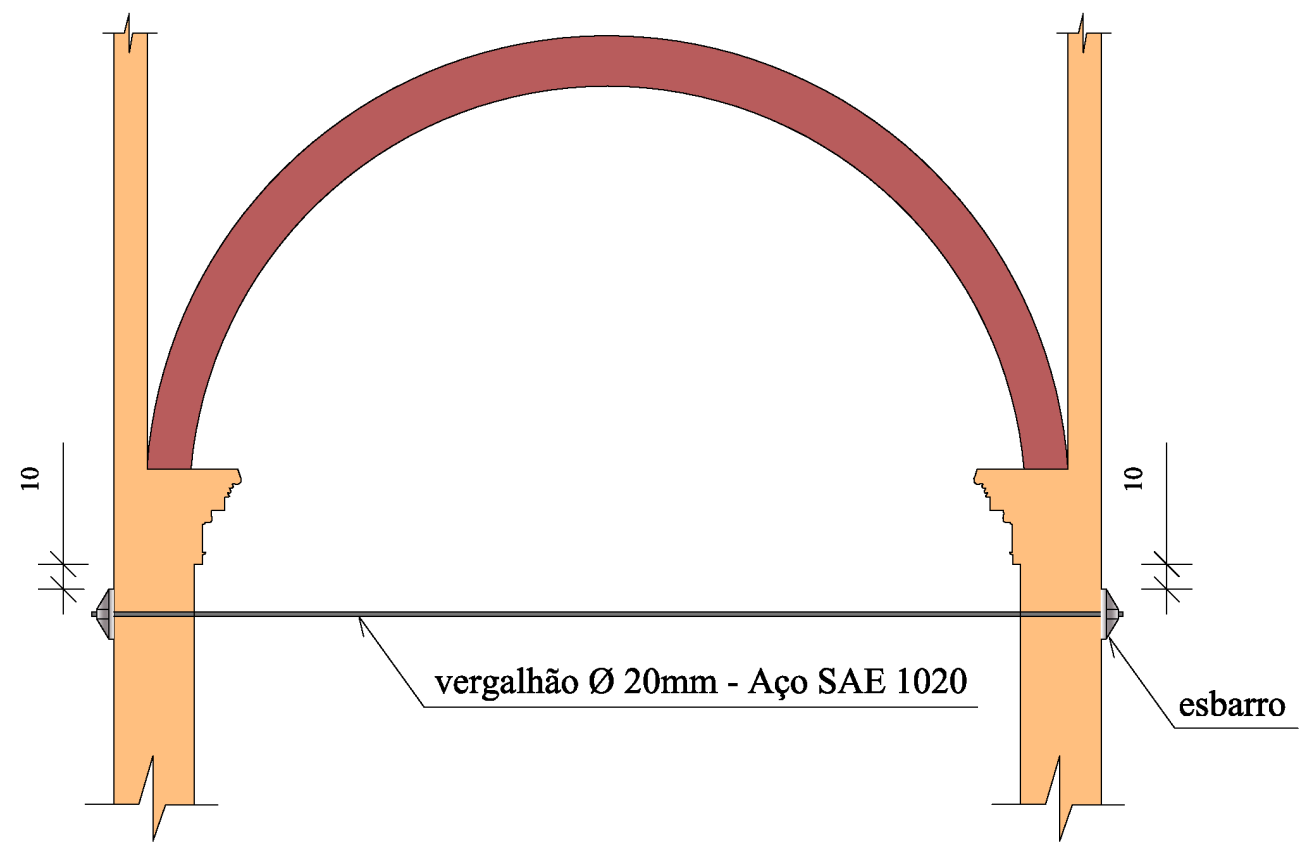

Figura 12. Sistema de estabilização proposto para a alvenaria, em corte (sem escala). 
Revista ALCONPAT, Volumen 4, Número 3, Septiembre - Diciembre 2014, Páginas 192- 201

Sabe-se que, em função do tempo, os tirantes apresentarão perda de tensão pela fluência do aço, cuja avaliação poderá ser feita em laboratório, por meio de ensaio de fluência do aço, com a utilização de extensômetros. Sendo realizado em um curto espaço de tempo, seus resultados não apresentam relação direta com aplicação prática e deverão ser extrapolados empiricamente para situações reais. Após esta determinação, quando necessário, será realizado novo aperto com chave de torque. Para atender a esta questão, novas ligas que apresentam maior resistência a esse tipo de deformação têm sido desenvolvidas.

\section{CONSIDERAÇÕES FINAIS}

Dentre os numerosos monumentos religiosos legados ao Brasil pela colonização portuguesa, destaca-se o de Santa Teresa da Bahia, o mais representativo de uma arquitetura tão peculiar e inconfundível como a de Portugal dos anos seiscentos. Ele é, em Salvador, a mais bela amostra de uma arte transplantada e adaptada ao novo ambiente.

Atualmente, a restauração é uma atividade interdisciplinar que envolve desde conhecimentos técnico-científicos até criatividade e sensibilidade para encontrar a solução mais adequada para cada caso. O presente estudo trata de uma análise estrutural e de proposta de consolidação da Igreja de Santa Teresa, em Salvador.

Teoricamente, foi feita uma contextualização do histórico e arquitetura da Igreja, passo importante para o desenvolvimento de processos de restauração e consolidação de monumentos. Posteriormente, foram obtidos os valores de empuxos com o software SAP 2000 Plus. Foi verificada a estabilidade do conjunto e desenvolvida uma proposta de estabilização das alvenarias.

Espera-se que esta metodologia possa ser disseminada e também utilizada em outras propostas que envolvam problemas de desaprumo de paredes por empuxos horizontais, pois abrange um tipo de intervenção que conserva os sistemas construtivos e estruturais, além dos materiais, incorporando peças delgadas, muitas vezes imperceptíveis aos olhos dos visitantes, e com custo módico. Ressalta-se, por fim, a importância deste trabalho, principalmente quando se trata de edificações de interesse histórico, artístico e cultural.

\section{REFERÊNCIAS}

Associação Brasileira de Normas Técnicas (1980), "NBR 6120 - Cargas para o cálculo de estruturas de edificações”, (Rio de Janeiro, Brasil: ABNT), p. 5

Bazin, G. (1956), “A Arquitetura Religiosa Barroca no Brasil” (São Paulo, Brasil: Editora Record), v. 2, p. 178

Calderón, V. de la V. (1970), "Biografia de um monumento - O Antigo Convento de Santa Teresa da Bahia”, (Salvador, Brasil: Estudos Baianos, Universidade Federal da Bahia), no 3, p. 244

Calderón, V. de la V. (1981), "50 Peças do Museu de Arte Sacra da Bahia”, (Salvador, Brasil: Universidade Federal da Bahia e Dow Química S.A.), p. 124

Oliveira, M. M. (2011), "Tecnologia da conservação e da restauração - materiais e roteiros: um roteiro de estudos", (Salvador, Brasil: EDUFBA: ABRACOR), p. 243

IPAC-BA (1978), "Inventário de Proteção do Acervo Cultural da Bahia - Monumentos do Município do Salvador - Bahia”, (Salvador, Brasil: Secretaria da Indústria, Comércio e Turismo), v. 1, p. 324 